\title{
Dolphin-Watching Boats Affect Whistle Frequency Modulation in Bottlenose Dolphins
}

\author{
Betzi Perez-Ortega ${ }^{1,2,3 *}$, Rebecca Daw ${ }^{4}$, Brennan Paradee ${ }^{4}$ Emma Gimbrere ${ }^{4}$ and \\ Laura J. May-Collado $2,3,4,5 *$
}

${ }^{1}$ Redpath Museum and Department of Biology, McGill University, Montréal, QC, Canada, ${ }^{2}$ Panacetacea, Saint Paul, MN, United States, ${ }^{3}$ Smithsonian Tropical Research Institute, Panama, Panama, ${ }^{4}$ Department of Biology, University of Vermont, Burlington, VT, United States, ${ }^{5}$ Centro de Investigación en Ciencias del Mar y Limnología, Universidad de Costa Rica, San José, Costa Rica

OPEN ACCESS

Edited by:

Aldo S. Pacheco,

National University of San Marcos,

Peru

Reviewed by:

Kerri D. Seger,

Applied Ocean Sciences,

United States

Stephanie H. Stack,

Pacific Whale Foundation,

United States

Bruno Díaz López,

Bottlenose Dolphin Research Institute

(BDRI), Spain

${ }^{*}$ Correspondence:

Betzi Perez-Ortega betziperez@yahoo.com

Laura J. May-Collado

Imaycoll@uvm.edu;

Imaycollado@gmail.com

Specialty section:

This article was submitted to

Marine Megafauna,

a section of the journal

Frontiers in Marine Science

Received: 16 October 2020

Accepted: 26 January 2021

Published: 17 February 2021

Citation:

Perez-Ortega B, Daw R,

Paradee B, Gimbrere E and

May-Collado LJ (2021)

Dolphin-Watching Boats Affect Whistle Frequency Modulation

in Bottlenose Dolphins.

Front. Mar. Sci. 8:618420.

doi: 10.3389/fmars.2021.618420
Bottlenose dolphins' whistles are key in social communication, conveying information about conspecifics and the environment. Therefore, their study can help to infer habitat use and identify areas of concern due to human activities. Here we studied the whistles of bottlenose dolphins (Tursiops truncatus) in two sites of the archipelago of Bocas del Toro, Panama, that contrast in boat traffic. Almirante Bay is a site dominated by taxiboats and Dolphin Bay is a major location for boat-based dolphin watching. Recordings were made using bottom-mounted hydrophones and from the research boat using an over-the-side hydrophone and a broadband recording system. A total recording effort time of 1,726 h was analyzed. Our results show significant differences in boat detection between sites, and a higher number of whistles detected per minute in the site with tour-boat traffic. Furthermore, whistle modulation accounted for most of the differences between sites, boat presence, and whistle types. Dolphin whistle modulation is thought to be a potential indicator of emotional states including danger, alertness, and stress. In this study, dolphin signature whistle modulation increased significantly with boat presence in both sites but changes in modulation were greater in Dolphin Bay where tour-boats directly and sometimes aggressively interact with the animals. These results support a potential association between whistle modulation and stress (or alertness). These findings indicate that if tour-boat captains behave more like taxi-boat captains by e.g., reducing the distance of approach and contact time during dolphin interactions, dolphin communication, and emotional state would be less disrupted. These measures are implemented in the national guidelines for whale-watching and are known to tourboat operators. The key to protecting these dolphins is in finding ways to effectively enforce these operator guidelines.

Keywords: dolphin-watching tourism, boat traffic, acoustic behavior, ecotourism, soundscape

\section{INTRODUCTION}

Bottlenose dolphins (Tursiops truncatus) have a rich acoustic repertoire used in a variety of contexts. They produce echolocation clicks to navigate and locate food ( $\mathrm{Au}, 1993)$, and social sounds such as whistles, calls, screams, barks, pops, and quacks when communicating with each other (Jones et al., 2020). Among the latter sounds, whistles are the most studied (e.g., Caldwell et al., 1990; 
Janik, 2009). These whistles are narrow banded, and frequency modulated and can be further categorized into "variants" or "signature" whistles based on their function and pattern of emission (Caldwell et al., 1990). Variant whistles are nonstereotypic sounds produced in a wide range of social contexts, often at a greater frequency than signature whistles (Sayigh et al., 1990; Rachinas-Lopes et al., 2017). In contrast, signature whistles are stereotypic sounds that encode information about individual identity and thus are used as contact calls (Caldwell et al., 1990). Signature whistles facilitate group cohesion (Janik and Slater, 1998; Janik, 2009), development and maintenance of male-male alliances (King et al., 2019), in communication between mother and calf pairs (Smolker et al., 1993); and they are also used as a greeting signal when dolphins groups meet in the wild (Quick and Janik, 2012). Signature whistle contour can vary in modulation which can be measured in terms of number of loops and number of inflection points (changes in the slope) (e.g., Janik et al., 1994; Esch et al., 2009). Studies of signature whistles during capture-release situations suggest that contour traits such as loop number and loop duration could indicate stress (Esch et al., 2009). Such associations between signature whistle contour characteristics and stress could help generate a better understanding of the impact of boat traffic and associated noise on dolphin communication. For example, May-Collado and Wartzok (2008) compared two neighboring populations of bottlenose dolphins in Costa Rica and Panama that had different levels of boat traffic and showed significant differences in dolphin whistle modulation (measured in number of inflection points). The dolphin population exposed to greater boat activity emitted significantly more modulated whistles than the one with low boat activity. Also, Marley et al. (2017) showed that Indo-Pacific bottlenose dolphins (Tursiops aduncus) produce whistles in which the number of inflection points increased with noise levels.

Bottlenose dolphins show a remarkable ability to modify their whistle acoustic frequencies to different acoustic environments (Morisaka et al., 2005; May-Collado and Wartzok, 2008) and behavioral activities (e.g., Díaz López, 2011). This ability has been widely documented in coastal dolphin populations where their acoustic environment is often dominated by small boats producing sounds at frequencies $(2-10 \mathrm{kHz})$ that overlap with the frequency range of dolphins (Wenz, 1962; Kelly et al., 2004; Bittencourt et al., 2014; Erbe et al., 2019). For instance, in response to small number of boats, dolphins are reported to increase whistle rate production, and change whistle frequencies and duration (e.g., Buckstaff, 2004; Guerra et al., 2014). For example, in the Cres-Lošinj Archipelago in Croatia (RakoGospiæ and Picciulin, 2016), the archipelago of Bocas del Toro in Panama (May-Collado and Wartzok, 2008), and in Japan (Morisaka et al., 2005), bottlenose dolphins produced whistles at frequencies that would minimize signal masking when ambient noise levels were higher as a result of anthropogenic activity. However, not all boat traffic affects dolphin acoustic behavior in the same way, and not all interactions are equal. In encounters with non-tourism vessels in the Fremantle Inner Harbor in Australia, Indo-Pacific bottlenose dolphins (Tursiops aduncus) whistles were higher in maximum, end, and delta frequencies in response to increasing noise (Marley et al., 2017). Similarly, in Lampedusa Island, Italy researchers found that in the presence of trawlers, dolphins produced whistles that were higher in most frequency variables, longer in duration, and more modulated (La Manna et al., 2013). In contrast, in Doubtful Sound, New Zealand, in the presence of tour-boat activity, changes in whistle frequency also depended on dolphin group composition (Guerra et al., 2014). Dolphin groups without calves responded to tour-boat presence by shifting to lower frequency whistles, whereas dolphin groups with calves shifted to higher frequency whistles (Guerra et al., 2014).

The archipelago of Bocas del Toro in the Caribbean waters of Panama is home to a small and genetically isolated population of bottlenose dolphins (May-Collado and Wartzok, 2008; BarragánBarrera et al., 2017). Photo-identification and residence patterns of site fidelity data suggest that these dolphins are distributed throughout the archipelago, with dolphins in Dolphin Bay showing the greatest levels of residency (May-Collado et al., 2017). Throughout the archipelago, dolphins are exposed to small taxi-boat traffic. However, the most prominent area of dolphin-taxi-boat overlap is at Almirante Bay, where boats use pre-established routes and schedules to transport people between the mainland and the main island of the archipelago (MayCollado et al., 2017). At Dolphin Bay, by contrast, resident dolphins are primarily exposed to tour-boat traffic. Here, dolphin-tour-boat interactions are often intense due to the lack of compliance with national regulations (Sitar et al., 2016). As a result, dolphins are often disrupted from foraging and social behaviors (Kassamali-Fox et al., 2020), and mother-calf pairs are often separated and sometimes injured (May-Collado et al., 2017). During dolphin-tour-boat interactions, dolphin groups produced high-frequency whistles (May-Collado and Wartzok, 2008), however, shifts in whistle frequency were particularly evident when the dolphins were engaged in foraging activities (May-Collado and Quiñones-Lebrón, 2014).

In this study, we evaluated the effect of two types of boat traffic: taxi-boats and tour-boats on dolphin acoustic presence, dolphin whistle detection rate, and acoustic structure in the dolphin population of Bocas del Toro, Panama. We hypothesized that dolphin whistle presence, detection rate, and acoustic structure would vary between types of boat traffic, because of the differences in which they interact concerning the number of boats and intensity of the interaction with the dolphins. The taxi-boats maintain schedules and pre-established routes (Figure 1) that result in less disruptive interactions with the dolphins. In contrast, tour-boats follow dolphins for long periods often in large numbers (2-40 boats) (May-Collado et al., 2017). May-Collado and Wartzok (2015) reported that in Dolphin Bay ambient noise [measured in $\mathrm{dB}$ Root Mean Square (RMS)] increased with the number of tour boats. As a result of the large boat aggregations (and associated noise) dolphin behaviors are often disrupted (Kassamali-Fox et al., 2020) and group members are separated (May-Collado et al., 2017). Under such circumstances, dolphins are likely to become stressed and more alert, and based on previous work by Esch et al. (2009) these emotional states can be detected in the modulation of the contour of signature whistle (e.g., loops and number of inflection points). 
Therefore, we expected that dolphins would produce more modulated signature whistles in the presence of boats than in their absence, and the pattern should be greater when interacting with tour-boats than with taxi-boats. Bottlenose dolphin whistles are the foundation of their fission-fusion society, and thus understanding how they are impacted by boat traffic can have important contributions in ongoing mitigation efforts.

\section{MATERIALS AND METHODS}

\section{Study Site}

This study took place in the archipelago of Bocas del Toro on the Caribbean coast of Panama. The archipelago consists of shallow and clear waters $<20 \mathrm{~m}$ in depth with coral reefs, mangrove forest and seagrass meadows surrounding the islands and it is home to a resident population of bottlenose dolphins. Genetic data classify this dolphin population as the "inshore" ecotype, which live in isolated and small populations (effective population size $\mathrm{Ne}=73$ individuals), and where both males and females show high levels of philopatry (see Barragán-Barrera et al., 2017). Isotope data indicate that these dolphins have a diverse diet as expected in an area with coral, mangrove, and seagrass communities; including fish like the mutton snapper, yellowfin mojarra, and the dwarf round herring (Barragán-Barrera et al., 2019). Dolphin watching in Dolphin Bay has grown to the point that now days up to 40 boats can be seen following the same group of dolphins within $1 \mathrm{~h}$. This is the result of lack of concurrent training and compliance of national whale watching guidelines (Resolution $\mathrm{N}^{\circ}$ Dm-0530-2017, 2017).

Recordings were done in two locations within the archipelago that differ in the type of boat traffic: Almirante Bay $(A B)$ and Dolphin Bay (DB) (Figure 1). In Almirante Bay, transport boats are the main type of boat activity. Three taxi-boat companies run every 30 min each way between mainland and the archipelago from 6 a.m. to 6 p.m. In Dolphin Bay, the main type of boat activity is related to dolphin watching. These tour-boats often approach the dolphins not following recommended national conduct guidelines. Dolphin watching boats arrive to Dolphin Bay every day between 9 a.m. to 12 p.m. Once a group of dolphins is spotted, they are approached by boats at distances of $50 \mathrm{~m}$ or less. As they are followed (sometimes for hours) tour boats tend to make rapid changes in speed and direction, resulting in mothercalf and group member separation (Sitar et al., 2016), disruption of key behaviors like foraging and socializing (Kassamali-Fox et al., 2020) and sometimes injuries and death due to boat collision (Trejos-Lasso and May-Collado, 2015; May-Collado et al., 2017).

\section{Recordings \\ Passive Acoustic Recordings Using Bottom-Mounted Hydrophones}

Recordings of dolphins and boats were made using the $\mu$ RUDAR-mK2 autonomous recorders $(-169 \mathrm{~dB}$ re: $1 \mathrm{~V} / \mu \mathrm{Pa}, 1-$ $96 \mathrm{kHz}$ ) from Cetacean Research Technology. The recorders were attached on a pole $1.5 \mathrm{~m}$ above the seafloor and anchored with a $\sim 30 \mathrm{~kg}$ block at $12 \mathrm{~m}$ depth. In Almirante, the location of the deployment was a sandy bottom with patches of coral reef and in Dolphin Bay the bottom was mainly muddy and seagrass with a few patches of coral reef. These bottom-mounted hydrophones recorded dolphin whistles without interference from the research boat and were scheduled to, simultaneously and continuously, record the acoustic environment in a 24-h cycle and at a sampling rate of $48 \mathrm{kHz}$ and 24 bits. Recordings were continuously made for up to 10 consecutive days, approximately once a month, between September 2017 and June 2018, in files of $30 \mathrm{~min}$ (Table 1). The recorder deployed in Almirante Bay malfunction several times resulting in unequal sampling of both sites. The total recording effort was 1,670 h (Dolphin Bay =1,406; Almirante $=264$ ).

The 1,670 h of passive acoustic recordings were then manually processed following our lab protocol for passive acoustic data. First, a 1-min recording sample was manually taken every $10 \mathrm{~min}$ resulting in six files of 1-min per hour, yielding a total of 10,705 1min files $(\sim 178 \mathrm{~h}$ ) (Almirante Bay $n=1,709$ 1-min files, Dolphin Bay $n=8,9961$-min files). These 1-min files were then uploaded to the online platform RFCx ARBIMON (Rainforest Connection, 2020) for sharing among collaborators and inspection using a spectrogram. Each 1-min file was annotated with information about the presence (1) or absence ( 0 ) of boats and dolphin sounds to create a $0-1$ matrix by time of day and site. Dolphin presence was marked as one when either or a combination of these sounds were present: echolocation clicks, buzzes, calls, and whistles. This procedure is entirely manual and is routinely followed in our lab to generate a sample of acoustic "vouchers" for all sites where passive acoustic recorders have been deployed as it facilitates identifying those recordings with sounds of interest.

Because our main interest is in the dolphin whistles, we used these 1-min files to locate in the original file (which was $30 \mathrm{~min}$ in length) dolphin whistles. This file was opened in RAVEN PRO 1.5 build 37 (Center for Conservation Bioacoustics, 2014) and a spectrogram was opened with a fast Fourier transform (FFT) size of 1,024 points, an overlap of 50\%, and using a 512-sample Hann window. All whistles that were manually detected in a consecutive fashion within a period were assigned to an "acoustic group." For example, if the 1-min file in RFCx ARBIMON indicated the presence of whistles at 1:10, we would then go to that point in the long recording and determine when the first and last whistle was detected in the recording. In total, five acoustic groups were identified for Almirante Bay, all distanced from each other by more than $2 \mathrm{~h}$ of recording time, while in Dolphin Bay 15 acoustic groups were identified, which were separated from each other by more than $3 \mathrm{~h}$ of recording time. Figure 2 is a flowchart of this process using an example spectrogram of the actual data. However, there is no guarantee that more than one dolphin group was recorded at the same time, or that what we considered was two independent acoustic groups were in fact not.

Once dolphin whistles were found we proceeded to (1) count all the whistles visible in the spectrogram within the acoustic groups and (2) classify dolphin whistles into signature and variants using the Signature Identification (SIGID) method (see Janik et al., 2013). This method consists of manually inspecting whistle contours. Because signature whistles are produced in bouts, any whistle of the same contour type occurring within 


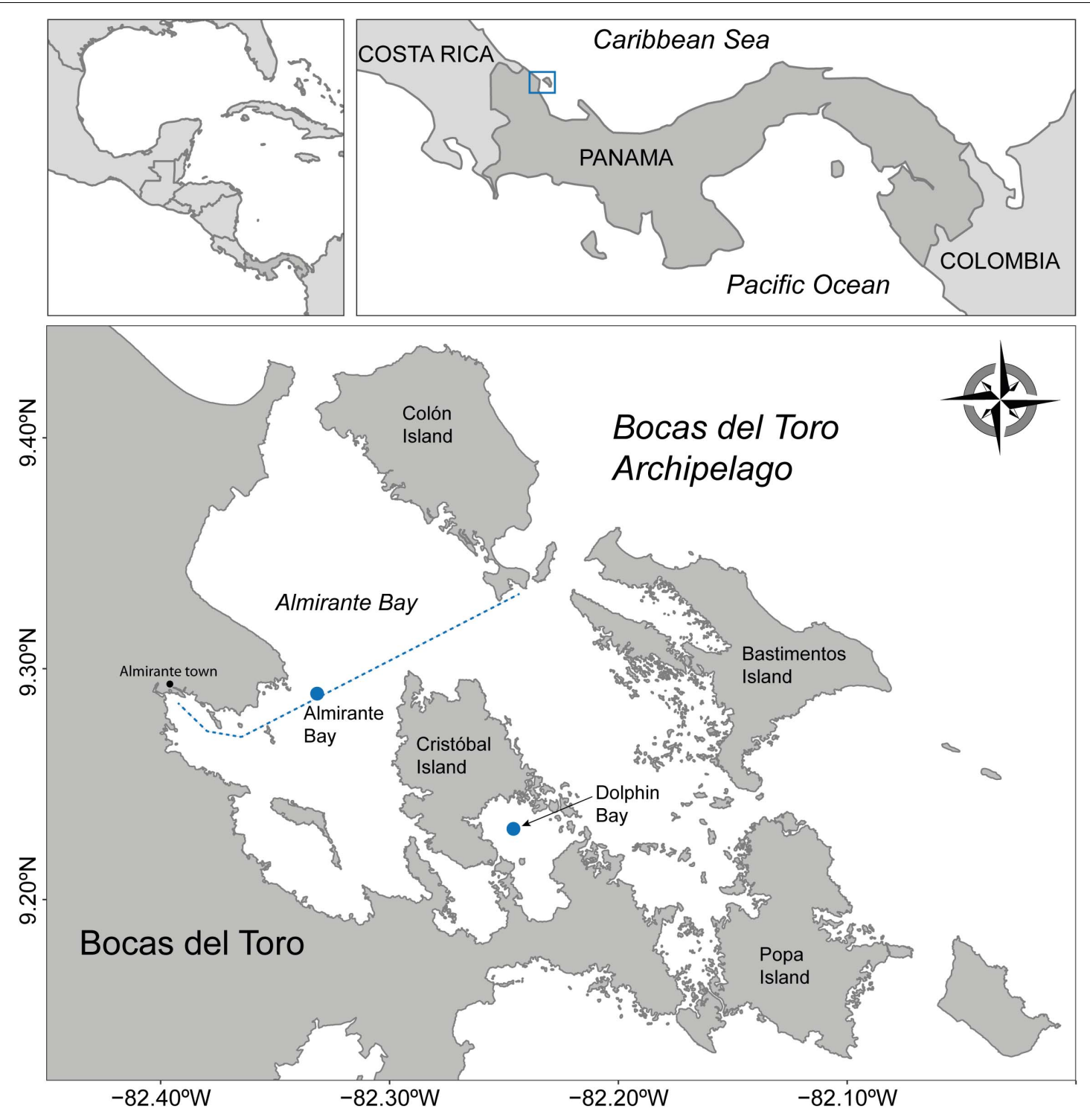

FIGURE 1 | Archipelago of Bocas del Toro, Panamá. Location of the two sites where bottom-mounted underwater hydrophones were deployed (Almirante Bay and Dolphin Bay). The dashed line corresponds to the main route used by taxi-boats from Almirante Bay to the main Island of the archipelago. Dolphin Bay is the location where dolphin watching activities takes place in the archipelago.

1-10 $\mathrm{s}$ is considered a signature whistle. For each acoustic group, we identified all possible signature whistles, and for variant whistles we maximized the selection of different whistle contour types. Since we do not know the actual size of the dolphin groups been recorded, we assumed the whistle selection protocol used in this study was conservative, while at the same time maximizing the representation of the whistle repertoire of the dolphins in this population.

Finally, only whistles with a clear and dark contour from start to end and a signal-to-noise ratio (SNR) above $8 \mathrm{~dB}$ were selected for acoustic data extraction. SNR was estimated using the Inband Power measurement in RAVEN ${ }^{1}$.

${ }^{1}$ https://ravensoundsoftware.com/knowledge-base/signal-to-noise-ratio-snr/
This selection process resulted in a total of 1,035 whistles (Almirante Bay $=242$; Dolphin Bay $=793$ ). For each of these whistles the following standard acoustic variables (e.g., Morisaka et al., 2005; May-Collado and Wartzok, 2008; Marley et al., 2017; Figure 2) were extracted: low frequency (LF) (measures the frequency in the lowest point in the contour), high frequency (HF) (measures the frequency at the highest point in the contour), duration (D), delta frequency (DF) (this is the difference between HF and LF), center frequency (CF) (represents the midpoint frequency between the lower and upper cutoff frequencies), peak frequency (PF) (frequency where the maximum amplitude occurred), and peak frequency contour number of inflection points (PFC Num Inf Pts) (measures the number 
TABLE 1 | Coordinates and deployment schedule of the bottom-based recorders at each site in the archipelago of Bocas del Toro.

\begin{tabular}{|c|c|c|c|c|c|c|}
\hline \multirow[t]{2}{*}{ Site } & \multirow[t]{2}{*}{ Coordinates } & \multicolumn{2}{|c|}{ Date } & \multirow[t]{2}{*}{ Total duration (h) } & \multirow[t]{2}{*}{ Total hour recorded } & \multirow[t]{2}{*}{ Total hours analyzed } \\
\hline & & Deployment & Retrieval & & & \\
\hline \multirow[t]{3}{*}{$A B$} & $9.289 \mathrm{~N},-82.332 \mathrm{~W}$ & Nov 8 & Nov 8 & 15 & 264 & 27.5 \\
\hline & & Jan 27 & Jan 27 & 14 & & \\
\hline & & Mar 28 & Apr 7 & 235 & & \\
\hline \multirow[t]{7}{*}{ DB } & $9.230 \mathrm{~N},-82.246 \mathrm{~W}$ & Sep 13 & Sep 18 & 120 & 1,440 & 148 \\
\hline & & Nov 8 & Nov 13 & 120 & & \\
\hline & & Jan 27 & Feb 6 & 240 & & \\
\hline & & Feb 28 & Mar 10 & 240 & & \\
\hline & & Mar 28 & Apr 7 & 240 & & \\
\hline & & May 3 & May13 & 240 & & \\
\hline & & May 28 & Jun 7 & 240 & & \\
\hline
\end{tabular}

AB, Almirante Bay (taxi-boats); DB, Dolphin Bay (tour-boats).

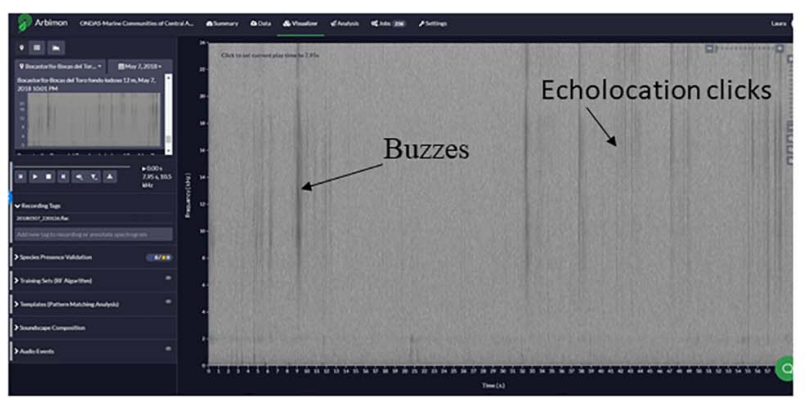

1-min recording 03/31/2018 at 9:11 p.m. with dolphin present

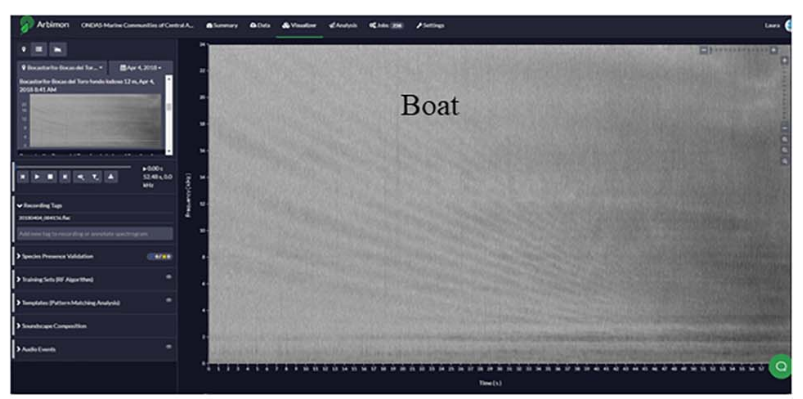

1-min recording 04/4/2018 at 8:41 a.m. with boat present

Signature whistle with a sine contour

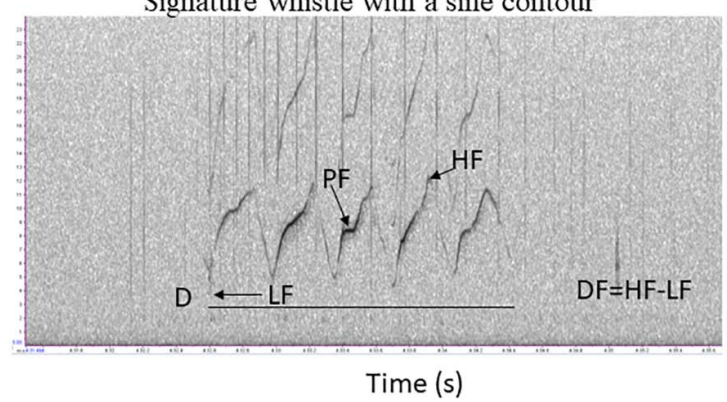

$\mathrm{HF}=$ high frequency $\mathrm{LF}=$ low frequency $\mathrm{DF}=$ delta frequency $\mathrm{PF}=$ peak frequency $\mathrm{D}=$ duration

Open continuous file that contain this time stamp

Time (s)

FIGURE 2 | Example of 1-min files used to locate recordings with dolphin whistles, and to create a presence-absence matrix for boat and dolphin presence. The spectrogram of the signature whistle at the bottom of the figure highlights some of the whistle acoustic variables measured in this study.

of times the slope changes sign in peak frequency contour slope) (Figure 2).

\section{Passive Acoustic Recordings From the Research Boat Using an Over-the-Side Hydrophone}

From 2004 to 2012 dolphins were recorded in Dolphin Bay from the research boat in the presence and absence of tourboats. Recordings were made using a broadband recording system that consisted of a RESON hydrophone 4,033 (-203 dB re:1 V/ $\mu \mathrm{Pa}, 1-140 \mathrm{kHz}$; RESON Inc., Goleta, CA, United States) was connected to an AVISOFT recorder and Ultrasound Gate $116 \mathrm{Hb}$ with discrete gain settings (sampling rate $400-500 \mathrm{kHz}$, 16 bit; Avisoft Bioacoustics, Berlin, Germany) that sent the signals to a laptop computer. The recording effort was $56 \mathrm{~h}$. All recording sessions were done in the presence of focal groups ranging from 2 to 10 individuals (May-Collado and Quiñones-Lebrón, 2014). A focal group was defined as a group of dolphins moving in the same direction and engaged in similar behaviors within five body lengths of each other (Mann, 1999). For each recording session recordings were made continuously and saved in files of $3 \mathrm{~min}$ in length. Each of these 3-min files was accompanied by an observation of the predominant surface behavior obtained by scan-group sampling every 3 min (Martin and Bateson, 2010). The presence or absence of tourboats was also noted for each 3-min recording. Dolphin group membership varied and based on photo-identification effort 
(photograph of natural marks on the dorsal fin of dolphins, a standard method to "mark" individual dolphins) the same 47 dolphins were recorded under different combinations and when engaged in three main behavioral activities: socializing, foraging, and travel (May-Collado and Wartzok, 2008; May-Collado and Quiñones-Lebrón, 2014). In an early analysis of this dataset, we found high intergroup variability (May-Collado and Wartzok, 2008) and that changes in whistle acoustic structure between the research boat and tour-boats occurred when the dolphins were engaged in foraging activities (May-Collado and QuiñonesLebrón, 2014). Foraging is the most disrupted behavior by tourboats in this dolphin population (Kassamali-Fox et al., 2020) highlighting the impact that tour-boats have on both surface and acoustic dolphin behavior. Given that signature whistles are specific to each dolphin, they are likely the reason for this variation, different combinations of individuals in a group will have different combinations of signature whistles (Quick and Janik, 2008). For this study, these past recordings were resampled and only whistles below $25 \mathrm{kHz}$ were selected to be able to compare to whistles obtained by the bottom-mounted recorder. Furthermore, we followed the same whistle selection process described in the passive acoustic section regarding classification of whistles into variants and signature and selection of a diversity of whistle contours that had a SNR above $8 \mathrm{~dB}$.

\section{Statistical Analysis}

Descriptive statistics were calculated for all boat and whistle variables. The Likelihood ratio with a Fisher's Exact test (Fisher, 1934) was used to test for association between boat and dolphin detections within sites, and a Kolmogorov-Smirnov Test (Smirnov, 1939) to determine if the diel distribution of these variables differs between sites. The temporal association between the mean of number of files with dolphin and boat for Almirante Bay and Dolphin Bay were evaluated using time series cross-correlation analysis. This analysis determines how much one variable is predicted to change in relation to the other variable. Dolphin whistle detection rate and frequency, duration, and modulation variables were not normally distributed even after being Box-Cox transformed (ShapiroWilk Test $P<0.05$ ) (Shapiro and Wilk, 1965). A permutation multivariate analysis of variance (PERMANOVA) (Anderson, 2001, 2006) was used to compare the dolphin whistle acoustic structure considering the effect of sites (Almirante Bay and Dolphin Bay), boat presence/absence, and whistle type (signature and variants). PERMANOVA assumption of homogeneity of multivariate dispersion was assessed with the homogeneity dispersion test ("betadisper"). Dolphin whistle acoustic variables were transformed to $y=\ln (y+1)$ as recommended by La Manna et al. (2013). Data was then transformed using Euclidean distance and the analysis was conducted with 999 permutations of the residuals under a reduced model. A dissimilarity percentage test ("simper") based on Bray-Curtis dissimilarity index was performed to find which whistle acoustic variables contributed the most to the observed differences. In Dolphin Bay, recordings were made from the research boat and a bottom-mounted hydrophone. To determine the potential impact of the research boat on dolphin whistle acoustic structure, a Mann-Whitney $U$ test (Mann and Whitney, 1947) was used. Specifically, we tested if dolphin whistle acoustic structure varied between recordings made only in the presence of the research boat and recordings with no boat present from the bottom-mounted hydrophone. To account for the effect size for the statistic we calculated the following test $n^{2}=z^{2} / \mathrm{N}-1$ (Fritz et al., 2012). We found significant differences in whistles delta frequency $(z=-2.78$, $\mathrm{df}=1, P=0.005)$, duration $(z=2.35$, $\mathrm{df}=1, P=0.018)$ and PFC Num Inf Points $(z=3.85$, df $=1, P<0.0001)$, but these variables explained less than $1 \%$ of the differences, suggesting that if there is an impact by the research boat, it is minimal. Therefore, we felt justified in merging the data from both recording methods for the PERMANOVA analysis. Descriptive and non-parametric analysis were performed in JMP 14. (SAS Institute, NC, United States) and SPSS Statistic 26 (IBM Corp., 2019). Time series cross-correlation and PERMANOVA were performed in the statistical software R v.4.0.3 ( $\mathrm{R}$ Core Team, 2020) and RStudio v.1.2.5042 (RStudio Team, 2020), using the "stats" package (R Core Team, 2020), and "vegan" package (Oksanen et al., 2020) respectively. The level of statistical significance for all analyses was $P<0.05$. To simplify reporting of results we will use the sites names to represent the type of boat activity, Almirante Bay for taxi-boats and Dolphin Bay for tourboats.

\section{RESULTS}

\section{Boat and Dolphin Detections}

After accounting for differences in sample size, boat and dolphin detections were significantly higher in Almirante Bay than in Dolphin Bay (Boats: Likelihood Ratio $=584.6, \mathrm{df}=1, P<0.0001$; Dolphins: Likelihood Ratio $=13.9, \mathrm{df}=1, P=0.0002$ ). However, in Dolphin Bay when dolphins were detected they produced 4.7 times more whistles per minute (Mean: 1.09 \#whistles/min, SD: 1.84, CV: 168.6, Range: 0-4.8) than dolphin in Almirante Bay (Mean: 0.23 \#whistles/min, SD: 0.78, CV: 344.7; Range: 0-0.73 \#whistles/min). Figure 3 shows the diel distribution of mean boat and dolphin detections for each site and the associated standard deviations bars. The diel distribution of boat presence between Almirante Bay and Dolphin Bay was significantly different (Kolmogorov-Test $=418, P=0.004$ ), but no significant differences were found in dolphin presence $(P>0.05)$. The times series analysis for Dolphin Bay and Almirante Bay indicates that the mean of boat and dolphin detections are not significantly correlated $(P>0.05)$; however, in Almirante Bay there was cross-correlation between the lag-6 and -3 , with the strongest correlation at lag -4 (Supplementary Figure 1). This indicates that a higher-than-average boat presence leads to a lower-than-average dolphin presence three to $6 \mathrm{~h}$ later. There was also a positive cross-correlation at $\operatorname{lag} 8$ and 9 , in which boat and dolphin presence increased simultaneously suggesting the influence of other external factors (Supplementary Figure 1).

\section{Whistle Acoustic Structure}

A total of 1,996 dolphin whistles were analyzed from the bottommounted and research boat hydrophones, 242 whistles from 
TABLE 2 | Statistical description of whistle parameters for bottlenose dolphins in two locations of the Archipelago of Bocas del Toro.

\begin{tabular}{|c|c|c|c|c|c|c|c|c|c|}
\hline Location & Statistics & $\begin{array}{l}\text { Whistle } \\
\text { Type }\end{array}$ & $\begin{array}{l}\text { Low } \\
(\mathrm{kHz})\end{array}$ & $\begin{array}{l}\text { High } \\
\text { (kHz) }\end{array}$ & $\begin{array}{l}\text { Peak } \\
(\mathrm{kHz})\end{array}$ & $\begin{array}{c}\text { Center } \\
\text { (kHz) }\end{array}$ & $\begin{array}{l}\text { Delta } \\
\text { (kHz) }\end{array}$ & $\begin{array}{l}\text { Duration } \\
\text { (s) }\end{array}$ & $\begin{array}{c}\text { PFC } \\
\text { Num Inf Pts }\end{array}$ \\
\hline \multirow[t]{2}{*}{$A B$} & Mean (SD) & Overall & 6.05 (2.92) & $10.37(4.52)$ & 7.53 (3.26) & $7.76(3.10)$ & 4.32 (3.58) & $0.63(0.55)$ & $25.46(27.10)$ \\
\hline & CV & & 48.26 & 43.65 & 43.33 & 39.90 & 83.76 & 87.60 & 106.38 \\
\hline \multirow[t]{2}{*}{$n=133$} & Mean (SD) & SW & $5.63(2.42)$ & $9.76(4.13)$ & $7.08(2.90)$ & $7.30(2.67)$ & $4.12(3.46)$ & $0.62(0.51)$ & $23.7(24.70)$ \\
\hline & $\mathrm{CV}$ & & 43.10 & 42.43 & 41.00 & 36.60 & 84.02 & 83.00 & 104.31 \\
\hline \multirow[t]{2}{*}{$n=109$} & Mean (SD) & WW & 6.55 (3.36) & $11.11(4.87)$ & $8.10(3.60)$ & $8.31(3.50)$ & $4.56(3.71)$ & $0.64(0.60)$ & $27.60(29.68)$ \\
\hline & CV & & 40.00 & 23.5 & 30.00 & 19.28 & 39.45 & 46.83 & 78 \\
\hline \multirow[t]{2}{*}{ DB } & Mean (SD) & Overall & $5.38(2.10)$ & 13.80 (3.95) & $9.24(2.94)$ & $9.31(2.21)$ & $8.42(4.18)$ & $0.96(0.71)$ & $234.10(232)$ \\
\hline & CV & & 38.72 & 28.66 & 31.83 & 23.80 & 49.70 & 73.78 & 99.11 \\
\hline \multirow[t]{2}{*}{$n=493$} & Mean (SD) & SW & $5.00(1.97)$ & $14.82(3.50)$ & $9.34(2.76)$ & $9.50(1.90)$ & $9.82(3.87)$ & $1.27(0.60)$ & 327 (255.20) \\
\hline & CV & & 51.40 & 44.00 & 44.42 & 42.00 & 81.30 & 93.00 & 107.35 \\
\hline \multirow[t]{2}{*}{$n=1261$} & Mean (SD) & WW & $5.52(2.10)$ & $13.40(4.05)$ & $9.20(3.00)$ & $9.24(2.34)$ & $7.87(4.17)$ & $0.84(0.71)$ & $196.93(211.32)$ \\
\hline & CV & & 38.10 & 30.26 & 32.68 & 25.37 & 53.03 & 84.94 & 78.34 \\
\hline
\end{tabular}

[Almirante Bay (AB): taxi-boats; Dolphin Bay (DB): tour-boats] for signature whistles (SW) and variant whistles (WW).

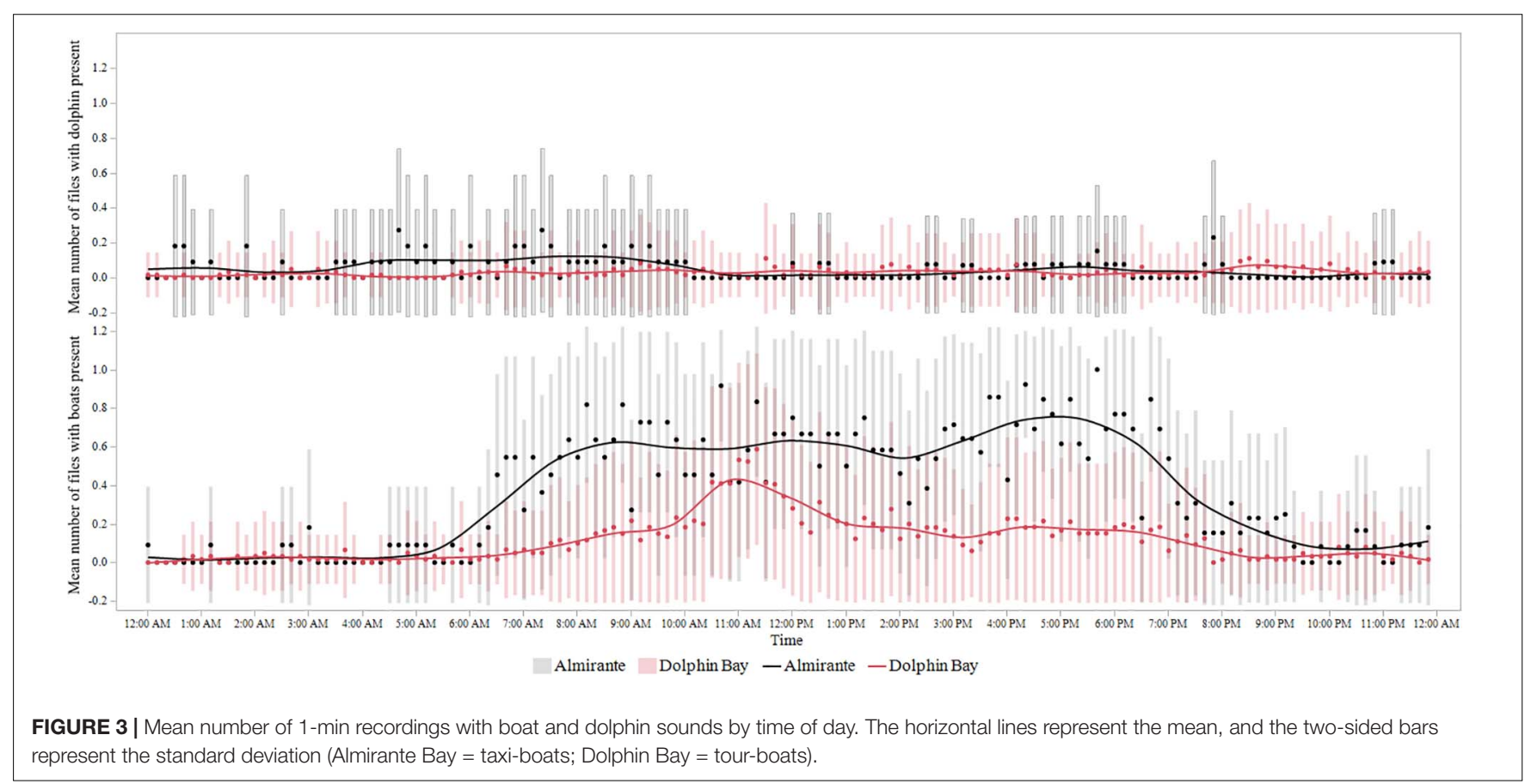

Almirante Bay (variant $=109$, signature $=133$ ) and 1,754 (variant $=1,261$, signature $=493$ ) from Dolphin Bay. Table 2 summarizes the statistical description of each dolphin whistle acoustic variable by site and whistle type. The multivariate PERMANOVA indicates that the overall dolphin whistle acoustic structure is significantly different between sites (Pseudo- $F_{1}$, $1995=529.64, P=0.001)$, boat presence (Pseudo- $F_{1,1995}=75.67$, $P=0.001$ ), and whistle type (Pseudo- $F_{1}, \quad 1995=104.94$, $P=0.001)$. Table 3 shows the PERMANOVA results for each dolphin whistle variable accounting separately for each factor and their interaction. Although they were significant in dolphin whistle frequency and duration between sites, boat presence, and whistle type; the dissimilarity percentage test indicates that about $60 \%$ of the variation in whistle acoustic structure was explained by the whistle modulation variables
PFC Num Inf Points ( site $=39.1 \%$, boat presence $=37.5 \%$, whistle type $=36.8 \%$ ) and delta frequency ( site $=20.1 \%$, boat presence $=18.70 \%$, whistle type $=18.70 \%$ ). Both modulation variables were significantly higher in Dolphin Bay, when boats were present, and when dolphins produced signature whistles (Figure 4).

\section{DISCUSSION}

Our results indicate that the nature of the two boat types affects differently the whistle acoustic structure of the residence dolphins. The effect was particularly important in the modulation of their individual signature whistles, highlighting the importance of distinguishing signature from 
TABLE 3 | Results from the PERMANOVA on the comparison of dolphin whistle acoustic structure using a Euclidean matrix, log-transformed data, and using 999 permutations.

\begin{tabular}{|c|c|c|c|c|c|}
\hline Whistle variables & Source & Df & Mean square & Pseudo-F & $\mathbf{P}$ (perm.) \\
\hline & Boat presence & 1 & 0.02 & 0.14 & 0.702 \\
\hline & Site $\times$ whistle type & 3 & 5.76 & 12.20 & 0.001 \\
\hline & Boat presence $\times$ whistle type & 2 & 0.44 & 1.41 & 0.235 \\
\hline \multirow[t]{4}{*}{ High frequency $(\mathrm{Hz})$} & Site & 1 & 27.77 & 236.99 & 0.001 \\
\hline & Whistle type & 1 & 3.10 & 26.48 & 0.001 \\
\hline & Site $\times$ whistle type & 3 & 30.58 & 88.31 & 0.001 \\
\hline & Boat presence $\times$ whistle type & 2 & 0.46 & 2.00 & 0.130 \\
\hline \multirow[t]{3}{*}{ Peak frequency $(\mathrm{Hz})$} & Site & 1 & 12.45 & 105.17 & 0.001 \\
\hline & Boat presence & 1 & 3.28 & 27.74 & 0.001 \\
\hline & Whistle type & 1 & $<0.01$ & $<0.01$ & 0.966 \\
\hline & Boat presence & 1 & 0.86 & 10.56 & 0.002 \\
\hline & Whistle type & 1 & 0.10 & 1.30 & 0.240 \\
\hline & Site $\times$ whistle type & 3 & 11.68 & 143.79 & 0.001 \\
\hline & Boat presence $\times$ whistle type & 2 & 0.86 & 10.56 & 0.001 \\
\hline \multirow[t]{5}{*}{ Delta frequency $(\mathrm{Hz})^{\star \star}$} & Site & 1 & 171.85 & 383.58 & 0.001 \\
\hline & Boat presence & 1 & 0.65 & 1.46 & 0.221 \\
\hline & Whistle type & 1 & 27.13 & 60.57 & 0.001 \\
\hline & Site $\times$ whistle type & 3 & 180.85 & 135.97 & 0.001 \\
\hline & Boat presence $\times$ whistle type & 2 & 1.55 & 1.74 & 0.167 \\
\hline \multirow[t]{2}{*}{ Duration (s) } & Site & 1 & 10.94 & 120.32 & 0.001 \\
\hline & Boat presence & 1 & 0.03 & 0.37 & 0.555 \\
\hline PCF Num. Inf. Points ${ }^{\star \star}$ & Boat presence $\times$ whistle type & 2 & 173.5 & 72.65 & 0.001 \\
\hline
\end{tabular}

Significant $P$ values are in bold; **variables that together explained $\sim 60 \%$ of the dissimilarity between sources.

variant whistles when studying the effects of boat traffic on dolphin communication.

The mean number of 1-min files with dolphin presence was greater in Almirante Bay than Dolphin Bay throughout the day, however, in Dolphin Bay dolphins produced 4.7 times more whistles per minute than in Almirante. Additionally, in Almirante Bay, the mean number of files with dolphin detections was slightly higher in the early morning when there were fewer boats present, whereas, in Dolphin Bay no significant patterns were found. However, it is important to note that we did not perform propagation experiments, and that differences in dolphin presence (measured as mean number of files with dolphin sounds and number of whistles detected per minute) may be due to differences in substrate characteristics between sites. Quintana-Rizzo et al. (2006) found that in Sarasota Bay, Florida dolphins detection range was limited by noise and substrate characteristics. The authors found that in shallow areas with a mud bottom, Sarasota dolphins whistles could be heard by other dolphins up to $2 \mathrm{~km}$, while in seagrass the acoustic contact was limited to $<500 \mathrm{~m}$. Dolphin Bay consists primarily of a muddy bottom, if such substrate allows for greater sound propagating distance as compared to the seagrass in Almirante, that could explain the greater number of whistles detected per minute in this location. Given the importance of bottom type in sound propagation the dolphin detection results should be taken with caution. Finally, it is also important to note that the number of whistle detected per minute can be influenced by a number of factors including group size (Quick and Janik, 2008), behavior and group composition (Hawkins and Gartside, 2010), and direct interactions with boats (e.g., Scarpaci et al., 2000; Buckstaff, 2004; 

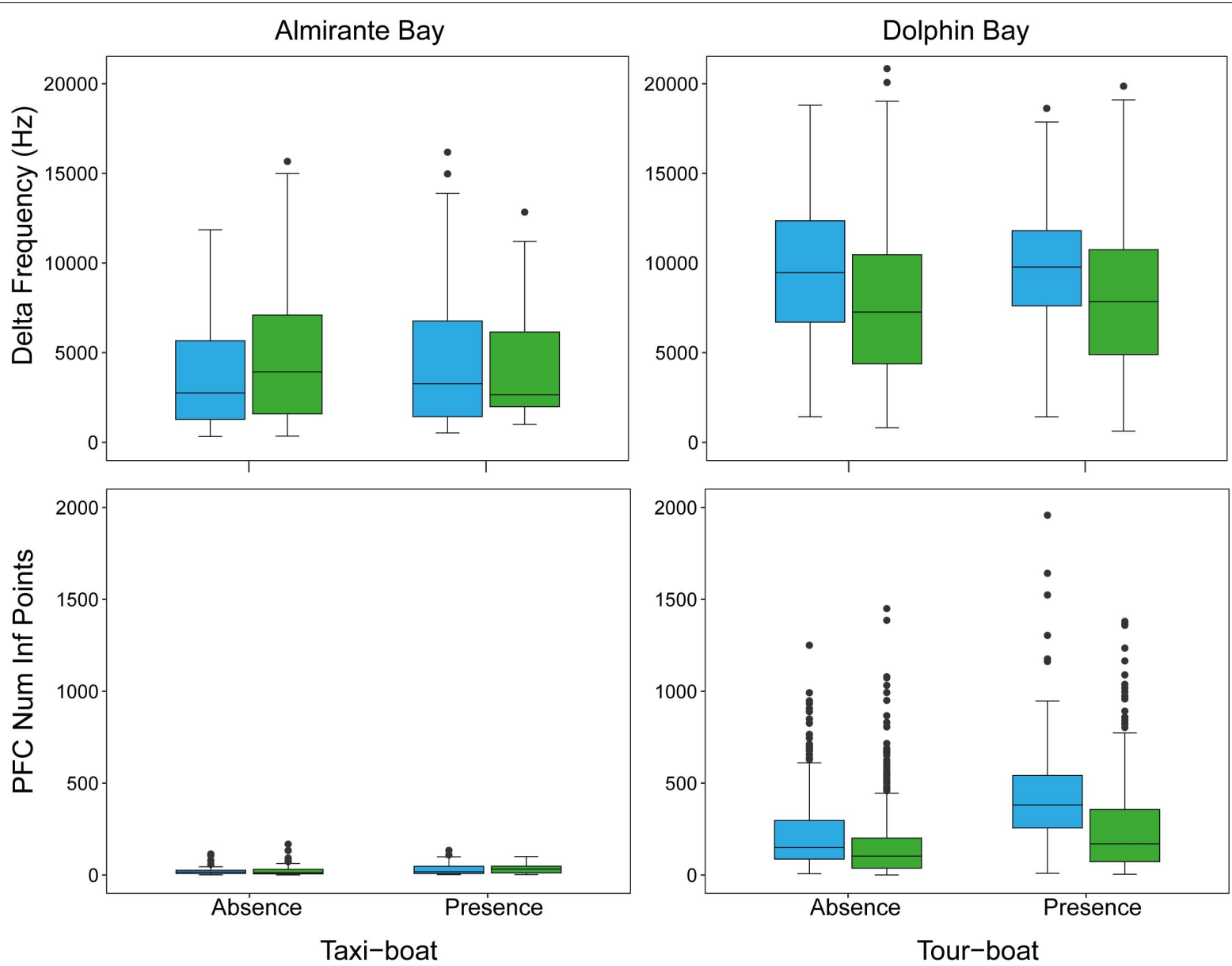

Type of whistle Signature

FIGURE 4 | Dolphin whistle frequency modulation measured as delta frequency ( $\mathrm{Hz})$ (top panel) and PFC Infl. Points (low panel) by site (Almirante Bay = taxi-boats; Dolphin Bay = tour-boats), whistle type, and boat presence.

Esch et al., 2009; Guerra et al., 2014), all of which we were unable to account for due to the passive acoustic recording nature of the recording system used in this study.

In animal acoustic communication, a sender's signal results in behavioral changes of one or more receivers (Bradbury and Vehrencamp, 2011). However, because the environment in which these animals live can affect signal propagation and detection (e.g., masking), it is expected that they can make frequency and temporal adjustments to optimize signal transmission (Morton, 1975). Such adjustments have been reported in frogs (Velásquez et al., 2018; Bignotte-Giró et al., 2019), birds (e.g., Boncoraglio and Saino, 2007), and some lineages of mammals including bats (Luo et al., 2015), primates (e.g., de la Torre and Snowdon, 2002; Tanaka et al., 2006), and dolphins (e.g., Papale et al., 2015; Fouda et al., 2018). Our results indicate that dolphins in the Almirante Bay and Dolphin Bay make frequency modulation adjustments depending on the type of boat traffic dominating their acoustic space (see Table 3). For example, in Almirante Bay, taxi-boat presence is high, spans a period ranging from
6 a.m. to 6 p.m., and follows pre-established routes, resulting in indirect interactions between dolphins and boats. Here, dolphins produced less frequency modulated whistles than those produced by dolphins in Dolphin Bay, the site where tourboats dominate the acoustic environment. Lower frequency modulation (simpler whistle contours) (Morisaka et al., 2005; Fouda et al., 2018) may counter the masking effects of the background noise made mainly by boats in the contexts of this study, enabling them to communicate more effectively. RakoGospiæ and Picciulin (2016) and Morisaka et al. (2005) found similar acoustic plasticity in the bottlenose dolphins of the Cres-Losinj Archipelago in Croatia and Indo-Pacific bottlenose dolphins in Japan, respectively.

In contrast, dolphins in Dolphin Bay emitted whistles with an increase in frequency of $\sim 2-4 \mathrm{kHz}$, an average increase of $30 \mathrm{~s}$ in duration, and $\sim 9$ times more modulation than the dolphin whistles recorded at Almirante Bay (see Table 3). These whistle variables showed lower coefficients of variation than those recorded in Almirante Bay. Similar "shifts" in frequency have 
been described in other sites (e.g., Papale et al., 2014; Heiler et al., 2016). For example, in Walvis Bay, Nambia, bottlenose dolphins did an upward shift of $1.99 \mathrm{kHz}$ in several whistle frequency variables when they were in the presence of tour-boats compared to the research boat (Heiler et al., 2016). Tour-boats have outboard engines that are loud (149-152 $\mathrm{dB}$ re $1 \mu \mathrm{Pa}$ root mean square at $1 \mathrm{~m}$ ) and broadband $(0.2$ and $40 \mathrm{kHz}$ ) (Jensen et al., 2009), and when boats are present in large numbers (up to 40 boats/h) as in the case of Dolphin Bay, noise levels increase (May-Collado and Wartzok, 2008, 2015).

Although changes in whistle frequency and duration were found between boat presence and absence, most of the variation was explained by whistle frequency modulation (delta frequency and PFC Num Inf Points). Changes in dolphin whistle modulation may provide insights into their "emotional" state during the interactions with tour-boats. Esch et al. (2009), compared signature whistle acoustic structure between brief capture-release (isolation of individuals from the group, including mother-calf pairs) and undisturbed conditions, and found an increase in whistle frequency modulation. The authors suggested that such changes in modulation could indicate stress or alertness. Since increased whistle frequency modulation has been linked to a more stressed emotional state in previous work, and our results found significant increases in whistle modulation between different boat type presence, it is reasonable to assume that Dolphin Bay is a more stressful environment than Almirante Bay. Overall, Dolphin Bay dolphins produced two times more modulated whistles when interacting with tour-boats than when followed by the research boat and when tour-boats were absent. Among the predicted impacts of tour-boats is stress (Rolland et al., 2012). Although the brief capture-release conditions of Esch et al. (2009) might not be representative of the harassment experienced by dolphins in Dolphin Bay during interacting with tour-boats, it may provide insights of their response to separation, which is often the product of the encounters with tour-boats in the bay (May-Collado et al., 2017; Kassamali-Fox et al., 2020).

Using a combination of passive acoustic monitoring data and recordings during focal follows, our study provides information about the variability of boat detections in two sites that contrast on boat activity. We show that dolphins respond differently to each of these boat activities primarily in their whistle acoustic structure. In natural conditions, dolphins' communicative signals are predicted to propagate over tens of kilometers (Janik, 2000); however, in heavily transited habitats such as the ones studied here, dolphins make adjustments in whistle acoustic variables associated with avoidance of signal masking. Furthermore, when accounting for dolphin whistles function (variants vs. signature whistles), our results agree with experimental studies showing a potential association between increase in signature whistles modulation and stress or alertness.

In summary, our results can be translated into mitigation strategies to reduce the impact of tour-boats on Dolphin Bay's dolphins. If tour-boat captains behave more like taxi-boat captains by (1) reducing distance of approach and contact time, (2) reducing the number of boats in contact with the dolphins, and (3) increasing time between interactions, their communication, and "emotional" state would be less disrupted.
These measures are contemplated in the national guidelines for whale-watching, which are known to most tour-boat operators. Furthermore, if tour companies make small changes in their schedules when visiting the bay, that could also lead to an important decrease in boats inside Dolphin Bay. Finally, the key for all these mitigation recommendations to work is enforcement. With ongoing efforts to make Dolphin Bay a protected area there is an opportunity for implementing these mitigating strategies and enforcing compliance.

\section{DATA AVAILABILITY STATEMENT}

The raw data supporting the conclusions of this article will be made available by the authors, without undue reservation.

\section{ETHICS STATEMENT}

The animal study was reviewed and approved by AICUC \#20190201-2022.

\section{AUTHOR CONTRIBUTIONS}

BP-O, LM-C, and RD contributed to the conception and design of the study. BP-O and LM-C collected field data. BP-O, BP, LM-C, RD, and EG processed field recordings, analyzed the data, and organized the database. LM-C and BP-O performed the statistical analysis. LM-C and BP-O wrote the first drafts of the manuscript. $\mathrm{RD}, \mathrm{BP}$, and $\mathrm{EG}$ revised and contributed to the draft manuscript. All authors contributed to manuscript revision, read, and approved the submitted version.

\section{FUNDING}

Funding for this project came from Rufford Small Grants, the ROC Grant from Waitt Foundation, SENACYT of Panama, Smithsonian Tropical Research Institute (STRI), Panacetacea.org, Conservation International Costa Rica, Society for Marine Mammalogy Travel Grant, Hendry Lab, Redpath Museum and Biology Department of McGill University, and May-Collado Lab.

\section{ACKNOWLEDGMENTS}

Special thanks to Rachel Collin, Urania Gonzalez, Plinio Gondola, and Gilberto Murray for their logistic support at the Smithsonian Bocas del Toro Field Research Station; and Demetrio Georget, Davis González, Cynthia Peña, Arcadio Castillo, and Maddy Tregenza for help in field work and data collection. We would also like to thank Andrew Hendry and Ingi Agnarsson for editorial comments and three reviewers which feedback significantly improve this manuscript. Data was collected under the scientific permit No. SE/A-75-17 from the Environment Ministry of Panama. AICUC \#2019-02012022 protocol was approved by Smithsonian Tropical Research Institute, Panama. 


\section{SUPPLEMENTARY MATERIAL}

The Supplementary Material for this article can be found online at: https://www.frontiersin.org/articles/10.3389/fmars. 2021.618420/full\#supplementary-material

\section{REFERENCES}

Anderson, M. J. (2001). A new method from non-parametric multivariate analysis of variance. Non-parametric ANOVA for ecology. Aust. Ecol. 26, 32-46. doi: 10.1111/j.1442-9993.2001.01070.pp.x

Anderson, M. J. (2006). Distance-based tests for homogeneity of multivariate dispersions. Biometrics 62, 245-253. doi: 10.1111/j.1541-0420.2005. 00440.x

Au, W. W. L. (1993). The Sonar of Dolphins. New York, NY: Springer-Verlag.

Barragán-Barrera, D. C., Luna-Acosta, A., May-Collado, L. J., Polo-Silva, C. J., Riet-Sapriza, F. G., Bustamante, P., et al. (2019). Foraging habits and levels of mercury in a resident population of bottlenose dolphins (Tursiops truncatus) in Bocas del Toro Archipelago, Caribbean Sea, Panama. Mar. Pollut. Bull. 145, 343-356. doi: 10.1016/j.marpolbul.2019.04.076

Barragán-Barrera, D. C., May-Collado, L. J., Tezanos-Pinto, G., Islas-Villanueva, V., Correa-Cárdenas, C. A., and Caballero, S. (2017). High genetic structure and low mitochondrial diversity in bottlenose dolphins of the Archipelago of Bocas del Toro, Panama: a population at risk? PLoS One 12:e0189370. doi: 10.1371/journal.pone.0189370

Bignotte-Giró, I., Fong, G. A., and López Iborra, G. M. (2019). Acoustic niche partitioning in five Cuban frogs of the genus Eleutherodactylus. Amphib Reptil. 40, 1-11. doi: 10.1163/15685381-17000170

Bittencourt, L., Carvalho, R. R., Lailson-Brito, J., and Azevedo, A. F. (2014). Underwater noise pollution in a coastal tropical environment. Mar. Pollut. Bull. 83, 331-336. doi: 10.1016/j.marpolbul.2014.04.026

Boncoraglio, G., and Saino, N. (2007). Habitat structure and the evolution of bird song: a meta-analysis of the evidence for the acoustic adaptation hypothesis. Funct. Ecol. 21, 134-142. doi: 10.1111/j.1365-2435.2006.01207.x

Bradbury, J. W., and Vehrencamp, S. L. (2011). Principles of Animal Communication, 2nd Edn, Sunderland: Sinauer Associates.

Buckstaff, K. C. (2004). Effects of watercraft noise on the acoustic behavior of bottlenose dolphins, Tursiops truncatus, in Sarasota Bay, Florida. Mar. Mamm. Sci. 20, 709-725. doi: 10.1111/j.1748-7692.2004.tb01189.x

Caldwell, M. C., Caldwell, D. K., and Tyack, P. L. (1990). "Review of the signaturewhistle hypothesis for the Atlantic bottlenose dolphin," in The Bottlenose Dolphin, eds S. Leatherwood and R. R. Reeves (Amsterdam: Elsevier), 199-234. doi: 10.1016/B978-0-12-440280-5.50014-7

Center for Conservation Bioacoustics (2014). Raven Pro: Interactive Sound Analysis Software (Version 1.5) [Computer Software]. Ithaca, NY: The Cornell Lab of Ornithology.

de la Torre, S., and Snowdon, C. T. (2002). Environmental correlates of vocal communication of wild pygmy marmosets, Cebuella pygmaea. Anim. Behav. 63, 847-856. doi: 10.1006/anbe.2001.1978

Díaz López, B. (2011). Whistle characteristics in free-ranging bottlenose dolphins (Tursiops truncatus) in the Mediterranean Sea: influence of behaviour. Mamm. Biol. 76, 180-189. doi: 10.1016/j.mambio.2010.06.006

Erbe, C., Marley, S. A., Schoeman, R. P., Smith, J. N., Trigg, L. E., and Embling, C. B. (2019). The effects of ship noise on marine mammals - a review. Front. Mar. Sci. 6:606. doi: 10.3389/fmars.2019.00606

Esch, H. C., Sayigh, L. S., Blum, J. E., and Wells, R. S. (2009). Whistles as potential indicators of stress in bottlenose dolphins (Tursiops truncatus). J. Mammal. 90, 638-650. doi: 10.1644/08-MAMM-A-069R.1

Fisher, R. A. (1934). Statistical Methods for Research Workers, 5th Edn, Edinburgh: Oliver \& Boyd.

Fouda, L., Wingfield, J. E., Fandel, A. D., Garrod, A., Hodge, K. B., Rice, A. N., et al. (2018). Dolphins simplify their vocal calls in response to increased ambient noise. Biol. Lett. 14:20180484. doi: 10.1098/rsbl.2018.0484

Fritz, C. O., Morris, P. E., and Richler, J. J. (2012). "Effect size estimates: current use, calculations, and interpretation": correction to Fritz et al. (2011). J. Exp. Psychol. Gen. 141:30. doi: 10.1037/a0026092
Supplementary Figure 1 | Cross-correlation function (CCF) analysis between the proportion of boats and dolphins by site. The $y$-axis represents the crosscorrelation coefficient, and the x-axis is the number of time periods (lag) that separate two time series. The horizontal dotted blue lines are the 95\% Confidence Intervals. The correlation is considered statistically significant at $p<0.05$ when the correlation coefficients fall outside these lines.

Guerra, M., Dawson, S., Brough, T., and Rayment, W. (2014). Effects of boats on the surface and acoustic behaviour of an endangered population of bottlenose dolphins. Endanger. Spec. Res. 24, 221-236. doi: 10.3354/esr00598

Hawkins, E. R., and Gartside, D. F. (2010). Whistle emissions of Indo-Pacific bottlenose dolphins (Tursiops aduncus) differ with group composition and surface behaviors. J. Acoust. Soc. Am. 127, 2652-2663. doi: 10.1121/1.3308465

Heiler, J., Elwen, S. H., Kriesell, H. J., and Gridley, T. (2016). Changes in bottlenose dolphin whistle parameters related to vessel presence, surface behaviour and group composition. Anim. Behav. 117, 167-177. doi: 10.1016/j.anbehav.2016. 04.014

IBM Corp. (2019). IBM SPSS Statistics for Windows, Version 26.0. Armonk, NY: IBM Corp.

Janik, V. M. (2000). Source levels and the estimated active space of bottlenose dolphin (Tursiops truncatus) whistles in the Moray Firth, Scotland. J. Comp. Physiol. A 186, 673-680. doi: 10.1007/s003590000120

Janik, V. M. (2009). “Acoustic communication in Delphinids," in Advances in the Study of Behavior, Vol. 40, eds M. Naguib, M. Vincent, and Janik (Burlington: Academic Press), 123-157.

Janik, V. M., King, S. L., Sayigh, L. S., and Wells, R. S. (2013). Identifying signature whistles from recordings of groups of unrestrained bottlenose dolphins (Tursiops truncatus). Mar. Mamm. Sci. 29, 109-122. doi: 10.1111/j. 1748-7692.2011.00549.x

Janik, V. M., and Slater, P. J. B. (1998). Context-specific use suggests that bottlenose dolphin signature whistles are cohesion calls. Anim. Behav. 56, 829-838. doi: 10.1006/anbe.1998.0881

Janik, V. M., Todt, D., and Dehnhardt, G. (1994). Signature whistle variations in a bottlenose dolphin, Tursiops truncatus. Behav. Ecol. Sociobiol. 35, 243-248. doi: 10.1007/BF00170704

Jensen, F., Bejder, L., Wahlberg, M., Aguilar de Soto, N., Johnson, M., and Madsen, P. (2009). Vessel noise effects on delphinid communication. Mar. Ecol. Prog. Ser. 395, 161-175. doi: 10.3354/meps08204

Jones, B., Zapetis, M., Samuelson, M. M., and Ridgway, S. (2020). Sounds produced by bottlenose dolphins (Tursiops): a review of the defining characteristics and acoustic criteria of the dolphin vocal repertoire. Bioacoustics 29, 399-440. doi: 10.1080/09524622.2019.1613265

Kassamali-Fox, A., Christiansen, F., May-Collado, L. J., Ramos, E. A., and Kaplin, B. A. (2020). Tour boats affect the activity patterns of bottlenose dolphins (Tursiops truncatus) in Bocas del Toro, Panama. PeerJ 8:e8804. doi: 10.7717/ peerj.8804

Kelly, C., Glegg, G. A., and Speedie, C. D. (2004). Management of marine wildlife disturbance. Ocean Coast Manag. 47, 1-19. doi: 10.1016/j.ocecoaman.2004.03. 001

King, S. L., Allen, S. J., Krützen, M., and Connor, R. C. (2019). Vocal behaviour of allied male dolphins during cooperative mate guarding. Anim. Cogn. 22, 991-1000. doi: 10.1007/s10071-019-01290-1

La Manna, G., Manghi, M., Pavan, G., Mascolo, F. L., and Sara, G. (2013). Behavioural strategy of common bottlenose dolphins (Tursiops truncatus) in response to different kinds of boats in the waters of Lampedusa Island (Italy). Aquat Conserv. 23, 745-757. doi: 10.1002/aqc.2355

Luo, J., Goerlitz, H. R., Brumm, H., and Wiegrebe, L. (2015). Linking the sender to the receiver: vocal adjustments by bats to maintain signal detection in noise. Sci. Rep. 5:18556. doi: 10.1038/srep18556

Mann, H. B., and Whitney, D. R. (1947). On a test of whether one of 2 random variables is stocastically larger than the other. Ann. Math. Stat. 18, 50-60.

Mann, J. (1999). Behavioral sampling methods for cetaceans: a review and critique. Mar. Mamm. Sci. 15, 102-122. doi: 10.1111/j.1748-7692.1999.tb00784.x

Marley, S. A., Salgado Kent, C. P., Erbe, C., and Parnum, I. M. (2017). Effects of vessel traffic and underwater noise on the movement, behaviour and vocalizations of bottlenose dolphins in an urbanised estuary. Sci. Rep. 7:13437. doi: 10.1038/s41598-017-13252-Z 
Martin, P., and Bateson, P. (2010). Measuring Behavior: An Introductory Guide, 3rd Edn, New York, NY: Cambridge University Press, 176.

May-Collado, L. J., Amador-Caballero, M., Casas, J. J., Gamboa-Poveda, M. P., Garita-Alpízar, F., Gerrodette, T., et al. (2017). "Ecology and conservation of cetaceans of Costa Rica and Panama," in Advances in Marine Vertebrate Research in Latin America, eds M. Rossi-Santos and C. Finkl (Berlin: Springer), 293-319.

May-Collado, L. J., and Quiñones-Lebrón, S. G. (2014). Dolphin changes in whistle structure with watercraft activity depends on their behavioral state. J. Acoust. Soc. Am. 135, EL193-EL198. doi: 10.1121/1.4869255

May-Collado, L. J., and Wartzok, D. (2008). A comparison of bottlenose dolphin whistles in the Atlantic Ocean: factors promoting whistle variation. J. Mammal. 89, 1229-1240. doi: 10.1644/07-MAMM-A-310.1

May-Collado, L. J., and Wartzok, D. (2015). The Effect of Dolphin Watching Boat Noise Levels on the Whistle Acoustic Structure of Dolphins in Bocas del Toro, Panama. Report to the International Whaling Commission. $\mathrm{SC} / 66 \mathrm{a} / \mathrm{WW} / 5$.

Morisaka, T., Shinohara, M., Nakahara, F., and Akamatsu, T. (2005). Effects of ambient noise on the whistles of indo-pacific bottlenose dolphin populations. J. Mammal. 86, 541-546.

Morton, E. S. (1975). Ecological sources of selection on avian sounds. Am. Nat. 109, $17-34$.

Oksanen, J., Blanchet, F. G., Friendly, M., Kindt, R., Legendre, P., McGlinn, D., et al. (2020). vegan: Community Ecology Package. R Package Version 2.5-7. Available online at: https://CRAN.R-project.org/package=vegan (accessed November 28, 2020).

Papale, E., Azzolin, M., Cascão, I., Gannier, A., Lammers, M. O., Martin, V. M., et al. (2014). Acoustic divergence between bottlenose dolphin whistles from the Central-Eastern North Atlantic and Mediterranean Sea. Acta Ethol. 17, 155-165. doi: 10.1007/s10211-013-0172-2

Papale, E., Gamba, M., Perez-Gil, M., Martin, V. M., and Giacoma, C. (2015). Dolphins adjust species-specific frequency parameters to compensate for increasing background noise. PLoS One 10:e0121711. doi: 10.1371/journal. pone. 0121711

Quick, N. J., and Janik, V. M. (2008). Whistle rates of wild bottlenose dolphins (Tursiops truncatus): influences of group size and behavior. J. Comp. Psychol. 122, 305-311. doi: 10.1037/0735-7036.122.3.305

Quick, N. J., and Janik, V. M. (2012). Bottlenose dolphins exchange signature whistles when meeting at sea. Proc. Biol. Sci. 279, 2539-2545. doi: 10.1098/rspb. 2011.2537

Quintana-Rizzo, E., Mann, D. A., and Wells, R. S. (2006). Estimated communication range of social sounds used by bottlenose dolphins (Tursiops truncatus). J. Acoust. Soc. Am. 120, 1671-1683. doi: 10.1121/1.222 6559

R Core Team (2020). R: A Language and Environment for Statistical Computing. Vienna: R Foundation for Statistical Computing.

Rachinas-Lopes, P., Luís, A. R., Borges, A. S., Neto, M., and dos Santos, M. E. (2017). Whistle stability and variation in captive bottlenose dolphins (Tursiops truncatus) Recorded in Isolation and Social Contexts. Aquat. Mamm. 43, 1-13. doi: 10.1578/AM.43.1.2017.1

Rainforest Connection (2020). RFCx Arbimon: Bio-Acoustic Analysis Platform. [Web-Based Platform]. Available online at: https://arbimon.rfcx.org/ (accessed 2020).
Rako-Gospiæ, N., and Picciulin, M. (2016). Changes in whistle structure of resident bottlenose dolphins in relation to underwater noise and boat traffic. Mar. Pollut. Bull. 105, 193-198. doi: 10.1016/j.marpolbul.2016.02.030

Resolution N Dm-0530-2017 (2017). GacetaOficial Digital N 28389-B, Panamá, República de Panamá. Panama: Ministry of the Environment.

Rolland, R. M., Parks, S. E., Hunt, K. E., Castellote, M., Corkeron, P. J., Nowacek, D. P., et al. (2012). Evidence that ship noise increases stress in right whales. P. Roy. Soc. B Biol. Sci. 279, 2363-2368. doi: 10.1098/rspb.2011.2429

RStudio Team (2020). RStudio: Integrated Development for R. Boston, MA: RStudio, Inc.

Sayigh, L. S., Tyack, P. L., Wells, R. S., and Scott, M. D. (1990). Signature whistles of free-ranging bottlenose dolphins Tursiops truncatus: stability and mother-offspring comparisons. Behav. Ecol. Sociobiol. 26, 247-260.

Scarpaci, C., Bigger, S. W., Corkeron, P. J., and Nugegoda, D. (2000). Bottlenose dolphins (Tursiops truncatus) increase whistling in the presence of "swim-with dolphin" tour operators. J. Cetacean Res. Manag. 2, 183-185.

Shapiro, S. S., and Wilk, M. B. (1965). An analysis of variance test for normality (Complete Samples). Biometrika 52, 591-611. doi: 10.1093/biomet/52.3-4.591

Sitar, A., May-Collado, L. J., Wright, A. J., Peters-Burton, E., Rockwood, L., and Parsons, E. C. M. (2016). Boat operators in Bocas del Toro, Panama display low levels of compliance with national whale-watching regulations. Mar. Policy 68, 221-228. doi: 10.1016/j.marpol.2016.03.011

Smirnov, N. V. (1939). Estimate of deviation between empirical distribution functions in two independent samples. Bull. Moscow Univ. 2, 3-16.

Smolker, R. A., Mann, J., and Smuts, B. B. (1993). Use of signature whistles during separations and reunions by wild bottlenose dolphin mothers and infants. Behav. Ecol. Sociobiol. 33, 393-402.

Tanaka, T., Sugiura, H., and Masataka, N. (2006). Sound transmission in the habitats of Japanese macaques and its possible effect on population differences in coo calls. Behaviour 143, 993-1012. doi: 10.1163/156853906778623617

Trejos-Lasso, L., and May-Collado, L. J. (2015). "Bottlenose dolphins Tursiops truncatus stranding in Bocas del Toro caused by boat strikes and fishing entanglement," in Proceedings of the International Whaling Commission, $S C / 66 a / W W 7$, London.

Velásquez, N. A., Moreno-Gómez, F. N., Brunetti, E., and Penna, M. (2018). The acoustic adaptation hypothesis in a widely distributed South American frog: southernmost signals propagate better. Sci. Rep. 8:6990. doi: 10.1038/s41598018-25359-y

Wenz, G. M. (1962). Acoustic ambient noise in the ocean: spectra and sources. J. Acoust. Soc. Am. 34, 1936-1956. doi: 10.1121/1.1909155

Conflict of Interest: The authors declare that the research was conducted in the absence of any commercial or financial relationships that could be construed as a potential conflict of interest.

Copyright (๑ 2021 Perez-Ortega, Daw, Paradee, Gimbrere and May-Collado. This is an open-access article distributed under the terms of the Creative Commons Attribution License (CC BY). The use, distribution or reproduction in other forums is permitted, provided the original author $(s)$ and the copyright owner $(s)$ are credited and that the original publication in this journal is cited, in accordance with accepted academic practice. No use, distribution or reproduction is permitted which does not comply with these terms. 